\title{
REDUÇÕES E ABRANGÊNCIA DA HERMENÊUTICA JURÍDICA
}

João Henrique Vasconcelos Arouck*

RESUMO: O artigo aborda o tema da discricionariedade sinalizando para duas versões da hermenêutica jurídica. Na versão reduzida, a hermenêutica serve para justificar a escolha da máxima de decisão encontrada em detrimento de outras soluções. Observa-se, contudo, que há processos decisórios que antecedem o evento da interpretação. Nesta outra versão, supõe-se que a tomada de decisão ocorre no âmbito da pré-compreensão e que as regras de interpretação não determinam a decisão, mas a justificam em nível argumentativo. $\mathrm{O}$ artigo traz a hipótese de que os condicionantes da discricionariedade são a formação teórica e o costume judicial.

Palavras-chave: Hermenêutica. Interpretação. Discricionariedade. Formação. Précompreensão. Juízo.

\section{REDUCTIONS AND LEGAL SCOPE OF HERMENEUTICS}

\begin{abstract}
The article addresses the issue of discretionary signaling for two versions of legal hermeneutics. In the reduced version, hermeneutics serves to justify the choice of the decision maxim found against other solutions. The article argues that there are decision-making processes that precedes the very event of interpretation. In a second version, it is assumed that decision-making occurs within the scope of pre-comprehension and that the rules of interpretation do not determine the decision but aims to justify it at the argumentative level. The article hypothesizes that the constraints of discretion are the theoretical formation and the judicial custom.
\end{abstract}

Keywords: Hermeneutics. Interpretation. Discretion. Formation. Pre-comprehension. Judgment.

\section{INTRODUÇÃO}

$\mathrm{O}$ artigo traz como tema central duas versões da hermenêutica jurídica. A primeira versão diz respeito ao sentido reduzido em que a hermenêutica cumpre uma função auxiliar para a solução de ambiguidades encontradas na fonte mensurada para fornecer a máxima de decisão. A segunda versão aponta para o sentido abrangente da hermenêutica jurídica. $\mathrm{O}$ alcance teórico dessa versão revela a existência de estruturas pré-compreensivas operadas na aplicação do direito. Em vista da temática adotada, o artigo tem como ponto de partida o problema da discricionariedade, subentendendo que a experiência da discricionariedade existe, mas não se confunde com o subjetivismo da arbitrariedade.

\footnotetext{
* Mestre em Direito (UFPa) e doutorando do Programa de Pós-Graduação em Direito da UFPa. Atua no marco teórico da hermenêutica jurídica.jharouck@yahoo.com.br
} 
Em consideração dos atuais parâmetros do debate hermenêutico, a colocação do problema se justifica por exigências naturalizadas no contexto de uma sociedade democrática cujo "cone de luz" alarga a elaboração interpretativa para mensurações cognoscitivas encobertas pela metodologia da hermenêutica jurídica naquela primeira versão. $\mathrm{O}$ artigo tem por objetivo demonstrar que a discricionariedade ocorre de forma controlada em virtude, precisamente, da pré-compreensão. Admite-se por hipótese, que o elemento predeterminante da escolha discricionária do aplicador é o tipo de formação teórica adotada para obter a máxima de decisão. As estruturas da formação teórica não sucedem de um ato de vontade isolado, mas do "comprometimento" do intérprete autêntico com a razão jurídica. Nessa relação se antecipam os elementos necessários de uma "tradição" colaborativa do sentido adequado. O artigo tem por objetivo demonstrar que tradição é essa e como ocorre tal comprometimento na hermenêutica jurídica em sentido reduzido e abrangente.

Em vista dos objetivos próprios de um artigo de revisão, adota-se a pesquisa bibliográfica para colocar o problema e corroborar uma ordem de hipóteses sobre o fenômeno da discricionariedade. As fontes bibliográficas levantadas, na teoria e filosofia do direito, bem como na literatura especializada da hermenêutica jurídica, permitiram contrastar modelos teóricos vigentes sobre a interpretação do direito. Em razão disso, adota-se uma abordagem que a princípio divide a hermenêutica jurídica em um sentido reduzido e em sentido abrangente.

\section{DA RELAÇÃO ENTRE PRÉ-COMPRRENSÃO E O CONCEITO HERMENÊUTICO DE FORMAÇÃO}

Palmer (2006, p. 21) identifica como próprio da hermenêutica filosófica o discurso sobre "o que é a própria compreensão, no seu sentido mais fundamental e existencial". O desenvolvimento dessa abordagem se deve ao intenso debate filosófico em torno da metodologia das ciências humanas ${ }^{1}$ nas obras de Dilthey, Heidegger e Gadamer. Ainda que uma problematização exclusiva da interpretação jurídica "esteja de um modo geral omitida" no entorno desse debate (PALMER, 2006, p. 43), parece consensual supor a pertença da hermenêutica jurídica ao desenvolvimento obtido pela abordagem fenomenológica da hermenêutica. Segundo análise extraída de Palombella (2005),

A hermenêutica gadameriana é de notável relevância para o direito, no qual foi constantemente utilizada sobretudo pelo alemão Joseph Esser. Em Gadamer como em Esser a hermenêutica é, por sua vez, atitude filosófica que

\footnotetext{
${ }^{1} \mathrm{O}$ termo Geisteswissenschaften é literalmente traduzido como "ciências do espírito", embora possa comportar tanto o significado latente das "ciências humanas" quanto o empirismo das "ciências morais".
} 
assume a linguagem como chave do acesso à ontologia, à realidade das coisas. Mas também a hermenêutica ratifica a inexistência de algo como a verdade semântica preestabelecida do texto normativo e atribui ao juiz um papel mais lato que a aplicação mecânica da lei (PALOMBELLA, 2005, p. 304).

A compreensão da hermenêutica como paradigma da tradição filosófica é notável na obra mais conhecida de Heidegger. Neste caso, a "hermenêutica" se dá como pensamento capaz de caracterizar, no dasein, o processo interpretativo de uma "filosofia primeira" no qual a linguagem do pensamento estaria sempre às voltas. Mas é na filosofia longamente depurada do naturalismo que se pode observar o início do processo de "racionalização" da hermenêutica. No tratado de Aristóteles (2013) verifica-se que o ato de interpretar já não se confunde com uma atividade de divinação, mas, sim, como ato de vontade operado nas formas mais "altas" e puras da "mente" (PALMER, 2006, p. 32). Para Aristóteles (2013) toda interpretação é necessariamente um ato preliminar que enuncia a "verdade" ou a "falsidade" das coisas dadas no referente do "ser" subsistente em categorias formais apreensíveis. Nesse referencial, a interpretação como juízo apofântico impõe a verificação das "coisas" enquanto (i) "verdadeiras" ou "falsas; (ii) nem "falsas" nem "verdadeiras" 2 " e, por fim, como (ii) "menos" ou "mais" verdadeiras, mas na medida em que se verifiquem proposições contraditórias sobre a mesma coisa.

O sentido aristotélico da hermenêutica corresponde a um paradigma clássico cuja problematização atenta para "a arbitrariedade e o subjetivismo nas disciplinas que têm a ver com a interpretação" (GRONDIN, 2012, p. 10). A abordagem clássica se mostra relevante quanto se problematiza, como neste caso, o nível de abrangência da metodologia geralmente aplicada na hermenêutica jurídica. Como método de abrangência reduzida, a metodologia aplicada se limita a estabelecer "standards de interpretação" 3 " os quais servirão como suporte aparentemente "dogmático" para justificar decisões previamente tomadas. A metodologia assim reduzida não entende como necessário problematizar o "subjetivismo" porque visa intencionalmente passar ao largo das estruturas que motivaram a decisão em seu referente fundamental de "verdade". A metodologia de abrangência reduzida estaria, portanto, a serviço

\footnotetext{
${ }^{2} \mathrm{O}$ exemplo para proposições nem falsas nem verdadeiras pode ser ilustrado como "jogo de linguagem" sem referente compartilhado uma vez que operado ao nível exclusivo da subjetividade.

${ }^{3}$ Os standards configuram mais um "nome", assim como a ideia de "regra", "cânone" ou "princípios" de interpretação, para uma mesma "coisa", a saber, o resultado depurado isoladamente de uma história do pensamento dogmático. Tal é a razão porque as regras de interpretação gramatical, lógica, teleológica, autêntica, histórica etc., são excluídas de seu referente dogmático para serem "utilizadas" como suporte de de uma argumentação que traduz uma estrutura da pré-compreensão como senso comum jurídico.
} 
de uma jurisprudência normativa caracterizada por abordar "o direito de fora" no sentido de conseguir "uma visão inteiramente objetiva do direito" (KELSEN, 2005, p. 238).

Com abrangência reduzida, a hermenêutica jurídica se mantém na posição de disciplina prática, servindo apenas para o "auxílio" de soluções animadas por um princípio legal suficientemente "necessário para se chegar à decisão" (LLOYD, 2000, p. 351). Nos casos em que há elementos vinculatórios suficientes, a hermenêutica jurídica não se reveste de qualquer interesse teórico, funcionando apenas como ornamento metodológico da "razão para decidir" (ratio decidendi). O positivismo se utiliza da hermenêutica com abrangência reduzida porque não acredita haver uma "razão teórica" relevante, nem necessidade prática para expandir a abrangência da hermenêutica jurídica para o referente da pré-compreensão. O ceticismo do método jurídico com relação ao alcance teórico da interpretação se justifica porque

O que certo juiz decidirá num caso concreto depende, na verdade, de um grande número de circunstâncias. Investigá-las todas está fora de questão. Sem levar em consideração o fato de que, hoje, ainda estamos inteiramente desprovidos dos métodos científicos para realizar tal investigação, também por outros motivos seria impossível submeter o juiz a tal investigação antes que ele anunciasse a sua decisão (KELSEN, 2005, p. 251).

O positivismo, de modo geral ${ }^{4}$, traduz o modelo do "conhecimento metódico" (GRONDIN, 2012, p. 66) que separa o "tempo" da hermenêutica em interpretação e aplicação do direito. Na radicalidade do modelo, a hermenêutica jurídica não seria nem mesmo parte integrante da experiência normal, pois as "exceções" de interpretação surgem apenas quando presente ambiguidades insanáveis na fonte do direito e no consequente "conflito" de teses. O referente pré-compreensivo encoberto nas práticas argumentativas do senso comum jurídico em vigor tem uma razão para que se encontre excluído da hermenêutica jurídica na função prática em que se encontra reduzida. Com base na observação de Lloyd (2000), a redução do alcance hermenêutico se explica porque

a existência nos países ocidentais de legislativos regularmente constituídos faz com que a divisão entre o ato de legislar e a interpretação judicial da lei pareça inteligível e justificável, e pensa-se que o exercício da circunspeção judicial é conducente à preservação da independência do judiciário. Por conseguinte, mesmo quando os tribunais estão manifestamente fazendo lei por suas decisões, eles tendem a furtar-se a confessar abertamente demais o que estão fazendo, no temor de serem acusados de usurpar as funções do legislativo. Daí uma tendência por parte dos tribunais a minimizar o elemento de escolha consciente em suas decisões e a expor seu raciocínio

\footnotetext{
${ }^{4}$ Fala-se de um modo geral, mas em consideração à história efeitual do positivismo jurídico. Para Streck (2017) é necessário distinguir sempre que possível o referente do "positivismo", ou seja, se se trata do "positivismo primitivo" das codificações do século XIX, do positivismo metodológico da Teoria Pura de Kelsen (2011) ou do "positivismo exclusivo" na forma verificada em Raz (2012).
} 
e argumentação na forma de deduções lógicas com base em regras (LLOYD, 2000, p. 343, grifo nosso).

Em contexto judicial diverso, um excerto de David (2002) aponta para o mesmo fenômeno - o encobrimento intencional das estruturas de pré-compreensão - considerando que:

o intérprete, que é de fato soberano - porquanto não existe recurso contra as decisões de um supremo tribunal -, dispõe de uma certa latitude. Mas ele gosta de dissimular a função criadora que desempenha na elaboração do direito, e dar a impressão deque o seu papel é simplesmente fazer a aplicação das regras formuladas por outrem. A medida segundo a qual, de fato, a sua obra é original e o cuidado que tem em dissimular esta originalidade variam segundo as épocas, segundo os países, segundo os ramos de direito e segundo as jurisdições que se considerem [...] certos juristas reconhecem que inicialmente sentem a decisão justa e procuram mais tarde justificá-la em direito; outros contestam com indignação este processo que, segundo eles, seria contrário à consciência dos juízes (DAVID, 2002, p. 139, grifo nosso).

Embora a decisão previamente tomada seja formaliza com o iter logicamente explicável dos elementos de escolha, a construção das premissas que permitiram ao intérprete obter a conclusão, é condicionada pelo referente obtido na pré-compreensão. Em posse de alternativas sedimentadas, a "interpretação" se realiza daí adiante por análise dos "méritos e deméritos de cada alternativa possível em face das demais, à luz dos fatos e experiência prévia que possuímos" (LLOYD, 2000, p. 339).

Observa-se por conta do desenvolvimento fenomenológico da "nova hermenêutica" (PALMER, 2006) que a cognoscibilidade dessa estrutura de linguagem supõe condições para ser levantada como a causa eficiente da interpretação. O tema da pré-compreensão é importante porque é nessa estrutura que se realiza o reconhecimento dos conteúdos intencionais suficientes para adequar o dado eventual dos fatos legislativos e jurisprudenciais à inteligibilidade consociada de intérpretes jurídicos. Supondo que o substrato da pré-compreensão consiste na rede da formação compartilhada - mesmo que dispersamente "segmentada" em pontos de partida correlativos -, tem-se que a experiência jurídica não poderia ser reduzida à experiência empírica do relativismo ao modo de uma discricionariedade semântica sobre os fatos legislativos e jurisprudenciais. A rede compartilhada na formação teórica conserva uma dinâmica que é própria da "hermenêutica da tradição", ou sejas, das fundações dogmáticas que conferem veracidade e adequação à interpretação obtida com a leitura dos padrões normativos.

Neste sentido, segundo análise de Grondin (2012, p. 69) “a tradição representa o que não é objetivável em um entendimento, mas o que o determina imperceptivelmente" como "horizonte de significados e intenções já aceites" (PALMER, 2006, p. 35). Em consequência disso, a rede intricada da formação teórica compartilhada seria algo próximo à ordem dos 
chamados “prejuízos legítimos”. Em razão da diferença que separa a validade dos pré-juízos entre legítimos e ilegítimos, o intérprete encontra-se invariavelmente comprometido com o sentido transmitido - o ser-afetado-pelo-passado -, mas apenas quando sabe distinguir quando deve ser o "paciente" e quando deve ser o "agente" do sistema herdado como "tradição". Na obra capital de Gadamer (2014), a exigência da "formação teórica” generaliza-se como conceito fundamental de todo o arcabouço das ciências humanas. A formação é necessária principalmente porque o homem não é por natureza o que deve ser. Hegel também teria percebido a formação como uma espécie de "elevação" corroborando que a

elevação à universalidade não se reduz à formação teórica nem significa apenas um comportamento teórico em oposição a um prático, mas cobre o conjunto da determinação essencial da racionalidade humana. A essência universal da formação humana é tornar-se um ser espiritual, no sentido universal. Quem se entrega à particularidade é inculto (ungebildet), é o caso de quem cede a uma ira cega sem medida nem postura. Hegel demonstra que, no fundo, essa pessoa carece de poder de abstração: não consegue abstrair de si e ter em vista um sentido universal, pelo qual paute sua particularidade com medida e postura (GADAMER, 2014, p. 48).

Já em Habermas (2004) a "tradição" se dá como "sujeito" de trajetórias interpretativas estruturadas no mundo da vida e reunificados no agir comunicativo dos agentes. Daí que a rede das práticas comunicativas formadas por uma série de atitudes, identidades, competências e modos de percepção. Nas palavras de Habermas (2004),

chamo cultura ao inventário de saber a partir do qual dos participantes da comunicação extraem as suas interpretações, quando pretendem entender-se sobre algo. A sociedade compõe-se das ordens legítimas através das quais os participantes da comunicação regulam a sua pertença a grupos sociais e asseguram a solidariedade. Nas estruturas de personalidade englobo todos os motivos e habilidades que permitem ao sujeito falar, agir, e, ao mesmo tempo, assegurar sua própria identidade. Se por um lado, para os que agem de uma forma comunicativa a cultura constitui o cone de luz, dentro do qual se deparam entidades, podendo ser representadas ou tratadas como algo de tangível, por outro, as normas e as vivências afiguram-se-lhes como algo que se inscreve no mundo social ou num mundo subjetivo, a que podem referir-se numa atitude conforme às normas (HABERMAS, 2004, p. 107, grifo do autor).

$\mathrm{Na}$ expansão da hermenêutica jurídica para o sentido abrangente, o conceito de formação importa porque o mesmo implica no desenvolvimento de uma "capacidade" para “julgar” adequadamente a variação empírica da experiência (GRONDIN, 2012, p. 64). Parece cada vez mais importante para a hermenêutica jurídica compreender a "consciência" que os juristas fazem do pensamento dogmático no contexto de aplicação do direito. Uma medida 
dessa relação encontra-se na teoria pós-empírica da ciência. Em vista da "solução de problemas" Thomas Kuhn (2011) considera que,

manuais, com exceção dos compêndios ou manuais introdutórios às obras originais, desempenham um papel apenas secundário. Em história, filosofia e nas ciências sociais, a literatura dos manuais adquire uma significação mais importante. Mas, mesmo nessas áreas, os cursos universitários introdutórios utilizam leituras paralelas das fontes originais, algumas sobre os clássicos da disciplina, outras relacionadas com os relatórios das pesquisas mais recentes que os profissionais do setor escreveram para seus colegas. Resulta assim que o estudante de cada uma dessas disciplinas é constantemente posto a par da imensa variedade de problemas que os membros de seu futuro grupo tentarão resolver com o correr do tempo. Mais importante ainda, ele tem constantemente frente a si numerosas soluções para tais problemas, conflitantes e incomensuráveis, soluções que em última instância ele terá que avaliar por si mesmo (KUHN, 2011, p. 209, grifo nosso).

Observa-se então que literatura do pensamento dogmático retoma a sorte dos conceitos prévios da "tradição" ao passo em que posiciona os "problemas" nos quais os juristas estão às voltas, sobretudo diante da premência de categorias "formais" da justiça como se dá na paridade, na proporcionalidade e na ideia de distribuição. A teoria pós-empírica de Kuhn (2011) sinaliza também para uma compreensão unificada da experiência jurídica a qual não submete a tradição ao empirismo relativo, nem submente a razão prática a uma "fundamentação" isolada da pré-compreensão dos agentes. Em vista do que se poderia chamar de "experiência unificada do direito", a posição da literatura dogmática se torna algo emblemático, considerando, conforme análise de Lloyd (2000), que nos sistemas derivados da Europa continental,

o direito desenvolveu-se a partir de seus alicerces no direito romano, por intermédio de uma tradição erudita e de raízes universitárias [...] E mesmo no sistema moderno, a profissão jurídica ainda recorre aos comentários eruditos e tratados de direito para a exposição científica de princípios legais e, portanto, eles continuam desfrutando de um status de autoridade excepcional, mesmo em face de decisões concretas de tribunais (LLOYD, 2000, p. 348).

A experiência jurídica não se resume à variação empírica dos fatos legislativos e jurisprudenciais porque sem a mediação dos esquemas conceituais da "tradição" os elementos puramente normativos não se colocam de "forma" adequada para funcionarem como meios de solução de problemas. É necessário supor que há relações efetivas que unificam as fontes do direito ao mesmo referente pré-compreensivo cujo substrato mais nítido é a formação teórica compartilhada dos operadores jurídicos. Neste sentido, segundo análise de David (2002), a caracterização da "tradição",

manifesta-se no fato de lhe caber a criação do vocabulário e das noções de direito que o legislador utilizará; manifesta-se, de modo ainda mais expressivo, no fato de caber à doutrina o estabelecimento dos métodos 
segundo os quais o direito será descoberto e as leis interpretadas. Acrescentamos ainda a isto a influência que a doutrina pode ter sobre o próprio legislador; muitas vezes este apenas se limita a efetivar as tendências que se desenvolveram, a registrar leis que foram preparadas pela doutrina. De modo algum se trata aqui de subestimar o papel do legislador; este papel é, na nossa época, de primeiro plano e nós consideramos como um progresso e como uma verdadeira necessidade (DAVID, 2002, p. 164, grifo nosso).

O alargamento da hermenêutica jurídica é necessário porque a redução das regras de interpretação a funções auxiliares deixa inexplorado a racionalidade operada em um espaço de decisão que se supõe "anômico" ou absolutamente "discricionário" (STRECK, 2017). No contexto de uma sociedade democrática, parece necessário solucionar, no campo estendido da hermenêutica jurídica, o conflito operado entre os atos insulares de "vontade" diante da précompreensão atuante na consciência de uma formação geral.

\section{O SIGNIFICADO DA PRÉ-COMPREENSÃO NA TEORIA DO BACKGROUND}

Em certa medida, o domínio da pré-compreensão hermenêutica pode ser explicado como intencionalidade característica dos eventos de representação sobre um "estado de coisas". Como elemento ativo da pré-compreensão, a intencionalidade não se confunde com a “intenção" isolada do agente. Para Searle (2010), neste sentido, a intencionalidade é uma categoria fundamental que explica o comportamento coletivo a partir de "regras" primárias subentendidas. O paradigma que explica o comportamento coletivo encontra-se na descrição de uma experiência compartilhada ao modo da "conversação". Ora, "não enxergamos esse fato porque nos ofuscam os artifícios analíticos tradicionais, que tratam toda a intencionalidade estritamente como uma questão do indivíduo" (SEARLE, 2010, p. 321).

Não se nega com isso a presença da intencionalidade individual, mas trata-se de um derivado da intencionalidade coletiva a qual permite, pela teoria do background, o entendimento e consecutiva aplicação desse entendimento coletivo na "interpretação" de enunciados empíricos ou de coisas "extremamente atuais". Searle (2010) corrobora com a ideia de um "entendimento prévio" ao nível da linguagem - princípio que também caracteriza o desenvolvimento da nova hermenêutica. A rede de crenças, opiniões e pressuposições atua para que o sujeito da experiência encontre condições tanto para emitir quanto para compreender enunciados numa estrutura conversacional. A rede do conhecimento atua, portanto, como o esquema geral que explica a tese de Searle (2010) sobre a existência background capaz de suportar intenções e justificar comportamentos,

"Eis então, para os nossos atuais propósitos, a tese do background: toda interpretação semântica, como aliás toda intencionalidade, funciona não só 
perante uma rede de crenças e outros estados intencionais, mas também mediante um background que não consiste num conjunto de conteúdos proposicionais, e sim em pressuposições que são, por assim dizer, préintencionais ou pré-proposicionais" (SEARLE, 2010, p. 324).

A linguagem a rede fornece as condições para uma "proposição" sobre "estados mentais" relativo às "coisas" no "mundo", ou seja, na forma como se encontram colocadas ou invariavelmente determinadas em um "estado de coisas". Numa perspectiva pós-empírica, o êxito da proposição não se submete à exposição das "causas" pelas quais as coisas se encontram num determinado estado - embora o intérprete possa voluntariamente fazê-lo. Nas ciências práticas de alcance teórico (como a hermenêutica jurídica), uma proposição bem-sucedida é aquela cujo conteúdo intencional se refere a um background compartilhado de antemão. A teoria do background e a experiência das conversações explicam porque uma frase pode ser entendida de diversos modos e porque uma semântica formal da própria linguagem pressuposta em "posições originárias" - restaria inócua. Em outro sentido, observa-se que quando a "rede" é comunicada por referentes absolutamente privados sucedem fenômenos como as "conversações insatisfatórias" travadas "entre pessoas oriundas de backgrounds radicalmente diferentes". Para Searle (2010, p. 353), "essas pessoas podem falar longamente sem que nada as aproxime da mútua compreensão".

De outro lado, porém, é possível haver conversações de conteúdo semântico mínimo cujo êxito se explica tanto pelo grau de compartilhamento referido ao background, quanto por conteúdos semânticos adicionados por informações colaterais. Em meio a essas premissas, pode-se dizer que o direito encontra melhores condições para ser interpretado quando se reconhece na elaboração semântica da regra jurídica um referente compreensivo elaborado no acordo fundamental da comunidade - perspectiva que se distingue da interpretação de "estados mentais" referido à linguagem privada dos “indivíduos" ou dos "autores” da fonte. Só podemos interpretar algo porque "certas áreas de nossa conduta dependem diretamente do background, e nosso entendimento de uma regra ou de qualquer conteúdo intencional sempre se dá em vista desse background" (SEARLE, 2010, p. 439). Portanto, se, de um lado, a normatividade da précompreensão pressupõe a "tradição" como o critério hermenêutico da verdade nas ciências humanas; a teoria do background pressupõe a rede de pressupostos compartilhados como critério de veracidade de proposições sobre "estado de coisas".

No compartilhamento da "rede" dos pressupostos válidos a noção de background colabora para o reconhecimento dos elementos da veracidade no uso pragmático da linguagem porque nesse background se constitui "as condições limitantes do significado e do 
entendimento, seja nas conversações, seja nas enunciações isoladas (SEARLE, 2010, p. 333). Disso se extrai que o conteúdo intencional da regra jurídica é mais ou menos válido na medida em que o referente normativo se liga ao padrão do comportamento aceito, inclusive no âmbito das práticas a serem adotadas no costume. Para Hart (2007, p, 151) isso se justifica porque "as regras jurídicas funcionam como tais na vida social: são usadas como regras, não como descrições de hábitos ou predições".

Por conseguinte, ninguém se escusa de cumprir lei alegando que não a conhece porque, em situações normais, a agência humana se confunde com o próprio posicionamento e aplicação de uma regra. Tal ocorre porque "se o nosso comportamento for posto em causa, estamos dispostos a justificá-lo por referência à regra" assim "como também na nossa crítica ao nosso próprio desvio ou ao dos outros relativamente a ela" (HART, 2007, p. 153). O posicionamento da regra no próprio padrão de comportamento demonstra que o conceito de regra de reconhecimento é mais abrangente do que uma "regra judicial costumeira" uma vez que a identificação do direito abrange grande parte senão todos os padrões de comportamento, subsistindo tanto na prática efetiva do sistema quanto "nas afirmações internas de validade feitas por aqueles que a usam para identificar o direito" (HART, 2007, p. 123). Ao funcionar como costume judicial, a regra de reconhecimento infunde no aplicador do direito jurídico a capacidade para "reconhecer atos, coisas e circunstâncias particulares como casos das classificações gerais que o direito faz" (HART, 2007, p. 137), assegurando condições interpretativas para que experiência hermenêutica não se submeta às variações empíricas do fato legislativo e jurisprudencial.

Portanto, segundo a teoria de Hart (2007) uma decisão jurídica satisfatória dependeria da regra de reconhecimento para corroborar "teses relacionadas não com o conteúdo factual das leis e sim com a sua conformidade a valores ou com princípios morais essenciais" (HART, 2007, p. 320). Na análise de Palombella (2005, p. 251) “a norma de reconhecimento basicamente dita critérios para definir ou não a pertença de certa norma ao ordenamento", mas “deve ser considerada critério compartilhado e público, não só como prescrição a que o juiz deve ater-se" (PALOMBELLA, 2005, p. 251). Tendo como ponto de partida a regra primária, a regra de reconhecimento compromete-se com as obrigações que "constituem o elemento básico da moral partilhada ou aceite de um grupo social” (HART, 2007, p. 184). Em consequência disso, o sistema passa a entender como necessário a postulação de regras secundárias sobre as "formas do julgamento". Por regras secundárias subentende-se o conjunto de regras adjetivas nas quais se "identificam os indivíduos que devem julgar”, definindo, daí 
em diante, um "processo a seguir" (HART, 2007, p. 162). Nesse ponto evidencia-se a natureza expandida da hermenêutica jurídica como disciplina de aplicação da regra de reconhecimento, o que justifica também porque "o conceito de lei deve ter o molde que melhor atenda às atividades e necessidades das pessoas que terão de lidar com a lei (ou seja, em diversos graus, todas as pessoas)" (RAZ, 2012, p. 190).

A execução de regras secundárias pelos tribunais aponta, fundamentalmente, para a estrutura conversacional que unifica legislação e jurisprudência sobre a mesma base de prejuízos de formação e background jurídico. Mas para que essa "conversação" seja bemsucedida é preciso que a transmissão do conteúdo intencional do significante jurídico encontre condições de reconhecimento. Da análise de Searle (2010) se extraem as seguintes condições para o êxito da conversação associada entre agências políticas e jurídicas no tocante às regras secundárias. Tais condições podem ser listadas com a seguinte análise: (i) o conteúdo semântico da regra deve ser suficiente para determinar ao aplicador "o que é certo e o que é errado", caracterizando condições abstratas para o sucesso ou fracasso da regra; (ii) o conteúdo intencional da regra pode não ser explícito, mas deve ser enraizado o suficiente para que o agente possa se tornar consciente da mesma; (iii) "os termos nos quais a regra está formulada devem pertencer ao repertório cognitivo do agente em questão", ou seja, deve lançar mão de conceitos disponíveis e estados de coisas conhecidos (SEARLE, 2010, p. 182); (iv) o conteúdo intencional da regra deve corroborar o senso prático do agente, ou seja, deve pressupor o agente como membro real de uma atividade cooperativa; (v) o conteúdo da regra deve ter função causal, estabelecendo um padrão normativo para agentes potencialmente posicionados; (vi) a regra poderá eventualmente lançar mão de estados mentais subjetivos no sentido de atuarem causalmente na produção de um comportamento ou de um conteúdo intencional derivado; (vii) nas regras explicativas, conforme Searle (2010, p. 221), o conteúdo proposicional "deve ser idêntico ao conteúdo proposicional na mente do agente cujo comportamento está sendo explicado".

Em resumo, vale dizer que a tarefa da compreensão exige um conjunto de práticas de fundo capazes de relacionar instâncias em estados intencionais experimentados como estados posicionados em um mesmo campo consciente capaz de assegurar o sentido experiência que para Searle (2010) tem como paradigma a prática de uma "conversação".

\section{JULGAMENTO E APLICAÇÃO DO DIREITO EM DIFERENTES PERSPECTIVAS}


Com a perspectiva adotada, algumas distinções se mostram necessárias em relação às duas problemáticas acima colocadas. Verifica-se que a suposta ausência de uma "faculdade do juízo" capaz de explicar a experiência de modo unificado é uma habilidade que se aproxima mais da virtude política do que da virtude exigida aos agentes que aplicam o direito. Não deixa de ser verdade, contudo, o fato de que as instâncias decisórias se vejam frequentemente às voltas com soluções que exigem um "julgamento" que tende a se colocar acima do "direito do ordenamento". Uma vez que do ato de julgar não se exige inteiramente o compromisso com a "formação" do pensamento dogmático, a complexidade que envolve o ato de julgar se aproxima mais da livre deliberação do legislador do que à tarefa do aplicador jurídico o qual se obriga tanto por compromissos da formação teórica quanto por regras secundárias ao chamado "direito do ordenamento".

O juízo como "julgamento" é problemático porque sinaliza a existência de um espaço aberto pela "vontade" como a "liberdade" que o agente admite ter para julgar. Nesse contexto podem colidir, segundo análise de Arendt (2008), as exigências não compartilhadas do "ego volitivo" em relação ao "ego pensante”. O “pensamento" como cálculo de meios apropriados e a "vontade" como o querer sobre algo possível só podem se tornar um "ato de juízo" verdadeiro quanto recorrem a uma disciplina que adequa a liberdade a princípios tradicionais de prudência: "uma exigência em qualquer atividade que envolva coisas cujo alcance está em poder do homem" (ARENDT, 2008, p. 332). Isto quer dizer, nas palavras de Lafer (2015, p. 424), que o juízo "confirma nosso lugar no mundo ao asseverar nossa conexão com a realidade através da responsabilidade inerente à mediação entre o particular e o geral”. Lafer (2010) atenta para o que vem a ser o "juízo" com o exemplo da experiência do "júri” retomado por Arendt (2008),

para observar que os jurados se veem igualizados pela tarefa e pelo lugar, tendo que deliberar sobre algo que não é do interesse privado e particular de nenhum deles. Eles estão interessados em algo no qual não têm nenhum interesse: o caso que compartilham, que é externo a eles, mas que se torna algo comum por razões que não são subjetivas. Esta imparcialidade - que permite ao júri sentir em comum e ao jurado julgar por sua própria cabeça - Hannah Arendt vê como virtude política, indispensável para que o juízo não seja comprometido pela intromissão, na esfera pública, dos sentimentos da vida íntima, conforme foi visto no capítulo anterior (LAFER 2015, p. 421).

Mas diferentemente da posição do "jurado", o "juiz" como intérprete autêntico do sistema jurídico encontra-se menos interessado na liberdade da vontade do que no direito do próprio ordenamento: o juiz não atua com a mesma liberdade de um legislador ou de um júri porque não se vê no direito de obliterar a "tradição" na adequação de fatos juridicamente 
relevantes à moldura semântica da norma. A ideia de uma "indispensabilidade" da razão prática presente na tradição do pensamento dogmático surge da observação de que

a premissa maior não é um dado, mas um construído que resulta da elaboração do juiz, fruto da interpretação da lei. Esta elaboração será tanto mais complexa epistemologicamente quanto mais abrangente for um ordenamento jurídico e os múltiplos significados nele contidos (LAFER, 2015, p. 391).

Pode-se dizer-se que "complexidade" da hermenêutica jurídica é consequência da tese que admite a equivalência das interpretações obtidas no ato de aplicação. Tal ocorre em Kelsen (2011, p. 390) porque o resultado a se obter de uma interpretação jurídica pressupõe a "fixação da moldura que representa o Direito a interpretar e, consequentemente, o conhecimento das várias possibilidades que dentro desta moldura existem". Com a tese da equivalência semântica de interpretações construídas por escalões normativos adequados à superioridade da constituição, Kelsen (2011, p. 391) reage a uma teoria hermenêutica exegética a qual subentendia "que a lei, aplicada ao caso concreto, poderia fornecer em todas as hipóteses, apenas uma única solução correta [...], e que a justeza [...] jurídico-positiva desta decisão é fundada na própria lei”. Em Kelsen (2011) o fenômeno que ocorre na instância de aplicação do direito consiste em algo mais próximo a uma "teoria da escolha racional" sobre alternativas subjetivamente ponderadas. Admitindo como natural o elemento discricionário da "política judiciária", Kelsen (2011) reduz a interpretação em um "ato da vontade", ou seja, como "fato" inexplicável da ciência jurídica.

Da exposição de Kelsen (2011), duas noções podem ser submetidas a teste, a saber, relativamente à ideia de que (i) a interpretação cognitiva se desenvolve "subjetivamente" em um processo insular de "política judiciária", e no tocante à (ii) rejeição da hipótese sobre a única interpretação correta, considerando que todas as interpretações possíveis se equivaleriam indistintamente na moldura semântica da norma jurídica. Com relação ao primeiro ponto, devese notar que na evolução do sistema romano-germânico toda agência jurídica passa a se desenvolver em bases cooperativas necessárias. É verdade, porém, que a “idolatria da lei, que dominou a doutrina do século XIX" levaram os juristas a utilizar "estratagemas para manterem essa tradição", mas apenas “quando esta obediência conduz a um resultado de justiça” (DAVID, 2002, p. 138). Soma-se a isso,

o fato de ser tão importante para o judiciário evitar envolver-se em decisões políticas que em casos de incerteza, quando opções tinham de ser inevitavelmente feitas, estas deviam sê-lo mais na base da coerência lógica do que em alguma base manifestamente extralegal, como o propósito social, a moralidade, a justiça ou a conveniência (LLOYD, 2000, p. 331). 
Disso se extrai que quando a base da justiça é o pressuposto da liberdade da vontade, a tarefa do juiz se aproxima da experiência do "julgamento" segundo o paradigma que ocorre mp “júri”, mas quando a categoria formal da justiça (paridade, proporção, igualdade, distribuição) é alçada como resultado de uma construção interpretativa do direito do ordenamento, o juiz se aproxima mais da tarefa interpretativa que o envolve na instância aplicadora. Tal ocorre porque,

de modo geral, nos países da família romano-germânica, a função judiciária dá lugar a uma carreira, que se abraça no início de sua vida profissional; é raro que os juízes sejam como nos países de common law, escolhidos entre os advogados que alcançaram grande reputação. Têm, por este fato, uma outra psicologia. Além das espécies concretas que lhes são submetidas, estão preparados, pela formação que receberam [...] a ver de um modo mais lato os problemas que lhes são submetidos; a sua visão do direito é menos estritamente técnica, menos insular; isto é reforçado pelo fato de que, ao lado deles, se encontra muitas vezes uma outra categoria de magistrados, com os quais eles têm estreitas relações: os magistrados do ministério público, cujo papel é valorizar junto deles o interesse da sociedade (DAVID, 2002, p. 155).

Se verdadeira a hipótese de equivalência das interpretações conferidas no mesmo quadro semântico, é possível verificar, como consequência disso, um cenário imprevisível de relativismo formal em prejuízo do "direito do ordenamento". Mas o relativismo fundado no direito exclusivo da cognição não se confunde com a situação em que as condições de fato podem de algum modo alterar as condições da aplicação. A perspectiva do relativismo é amenizada quando se supõe que a interpretação é de natureza essencialmente construtiva embora condicionada à “ideia do ordenamento". Na teoria de Dworkin (2007, p. 64) a ideia corresponde à teoria da interpretação construtiva a qual impõe "um propósito a um objeto ou prática, a fim de torná-lo o melhor exemplo possível da forma ou do gênero aos quais se imagina que pertençam”.

Se, na análise de Palmer (2006), a nova hermenêutica aborda a interpretação desde a posição existencial do agente no interior de uma história dos conceitos, a "teoria geral da interpretação" de Betti (2004) recebe da nova hermenêutica o problema da atualização da lei segundo as exigências do meio social, reconciliando-a com os princípios gerais de uma intepretação objetiva dos textos jurídicos e cujo sujeito encontra-se "estimulado e movido a entender por interesses da vida presente", representando um "modo de pensar" como "forma da vontade realizada" (BETTI, 2004, p. 40). Impõe-se para tanto que o conteúdo intencional do texto jurídico esteja referido, como visto de modo abrangente em Searle (2010), a comportamentos nos quais a interpretação se torna socialmente reconhecível. 
Em Betti (2004, p. 53), “o ofício do intérprete é unicamente aquele de pesquisar e entender o sentido da manifestação (passada) do pensamento alheio" como experiência presente e atual. O aspecto "voluntário" não é excluído, pois funciona para que o intérprete se coloque na perspectiva mais favorável à perspectiva correta do texto. A "vontade" se traduz em Betti (2004, p. 55) como "disposição congenial e fraterna para com aquilo que é objeto de interpretação". Observa-se de Betti (2004) a função reprodutiva da hermenêutica em sentido transitivo: o intérprete não visa exaurir isoladamente o sentido jurídico, pois dirige-se ao público "numa dimensão espiritual diferente daquela em que o pensamento é originalmente concebido" (BETTI, 2004, p. 69). Betti (2004) pressupõe no texto emitido na liberdade do legislador uma objetividade que corresponde ao texto no qual o intérprete deve identificar elementos abstratos de uma "obra" com características próprias de (i) autonomia; (ii) necessidade; (iii) coerência e (iv) racionalidade interior.

Mas a hipótese sobre uma "máxima de decisão" mais adequada do que outras máximas correspondentes - tese da equivalência -, só pode ocorrer quando a "obra" apresenta uma "lei de formação" referida ao pensamento dogmático. A tradição é um valor de verdade porque compreende conceitos jurídicos da forma exata como "vieram a ser". Para extrair da "lei de formação" uma máxima de decisão mais "conformada" do que outras máximas correlativas, Betti (2004, p. 81) recorre ao que chama de interpretação técnico-científica, pois para compreender a história do direito "segundo a lógica interna dos institutos e dos princípios" é preciso que a interpretação atue "com os instrumentos conceituais da dogmática". No âmbito da função reprodutiva, quais seriam, pergunta-se, os requisitos para que a interpretação técnicocientífica atue como uma espécie de "cânone"? Pode-se elencar de Betti (2004, p. 82) precondições relativas ao (i) nível de familiarização do intérprete com os esquemas conceituais da dogmática e (i) a função adquirida pelos institutos e princípios jurídicos com o passar do tempo. Em ambos os casos, se encontrados "problemas de formação" no texto jurídico, deverá o agente integrar no plano interpretativo uma sorte de "princípios" de fontes contemporâneas no intuito de sanar representações conceituais ausentes.

Entende-se que as precondições elencadas são afinal necessárias porque sem o suporte do pensamento dogmático, "o jurista procederia às cegas com o empirismo do profano" (BETTI, 2004, p. 107). Além disso, "para dominar a matéria da vida social, todo direito, mesmo que primitivo, [o jurista] precisa de tipos e categorias que se encontrem em lógica correlação e coerência entre si” (BETTI, 2004, p. 103). A presença do pensamento dogmático não depende inteiramente da integração voluntária do intérprete: os instrumentos da dogmática são 
precondições da hermenêutica porque funcionam como "esquema geral de análise e medida dos fatos e das relações jurídicas" determinando-se como o próprio "sistema de unidade de medida" do direito (BETTI, 2004, p. 126). Para Emilio Betti (2004, p. 18) até mesmo a sustentação de enunciados pelo legislador em posições originárias dependeria da "estrutura dogmática" para “orientar a vida social na diretiva de suas avaliações". Ademais disso, a presença da dogmática se justifica ainda porque

ao sistematizar, a Dogmática Jurídica mantém, nos sistemas sociais complexos, o Direito como um subsistema diferenciado. Este é diferenciado dos demais na medida em que é autônomo, isto é, em que é capaz de impedir que um evento qualquer nos demais subsistemas sociais seja um evento dentro dele. Isso é conseguido na medida em que o Direito, como subsistema, regula por si o que deve e o que não deve ser juridicizado, e, sendo juridicizado, o que é jurídico e o que é antijurídico (FERRAZ JUNIOR, 2015, p. 124).

Em Betti (2004, p. 18), a função da dogmática apresenta características próprias como o discurso racional que busca (i) "escolher" para resumir ou "simplificar" conteúdos tradicionais; (ii) distinguir nos fatos subjacentes conexos à função dogmática os elementos relevantes e irrelevantes; (iii) classificar fenômenos sociais em esquemas e categorias que os tornem acessíveis à disciplina jurídica do intérprete e (iv) atribuir coerência lógica "às avaliações que determinam e justificam as soluções legislativas dos problemas" (BETTI, 2004, p. 9). Em função desses propósitos, a "Dogmática faz com que seu discurso não se confunda com as sistematizações e regularidades empíricas do comportamento, nem com generalizações dessas regularidades, nem, ainda, com um conjunto de regras de natureza [puramente] lógicoformal” (FERRAZ JUNIOR, 2015, p. 187). Em consequência da relação categorial que se estabelece entre o pensamento dogmático e a hermenêutica jurídica, verifica-se, em resumo, que a função jurisdicional da interpretação não se aplana ao nível da discricionariedade porquanto permanece "sempre vinculada e subordinada à linha de coerência lógica que se demonstra imanente à ordem jurídica, considerada em sua totalidade orgânica” (BETTI, 2004, p. 29).

\section{CONCLUSÃO}

À guisa de conclusão, pode-se dizer que em vista de parâmetros atuais, a hermenêutica jurídica já não concebe a divisão entre "teoria" e "prática" da interpretação. O esquema atual parece apontar para dois "campos" que colaboram conjuntamente para o plano da argumentação jurídica, embora esse plano não esteja comportado nos objetivos do presente artigo. Dado que a interpretação é um evento da ordem do ser, a hermenêutica jurídica tende a manter o sentido reduzido na forma de uma "metodologia" da aplicação. Neste caso, a hermenêutica jurídica

Rev. de Argumentação e Hermenêutica Jurídica | e-ISSN: 2526-0103| Goiânia| v. 5 | n. 1 | p. 17-35 | Jan/Jun. 2019 
refere-se à experiência que postula uma norma jurídica para uma ordem de fatos contornados nos limites da consciência. Em razão da natureza prática dessa experiência, verifica-se que em certas ocasiões a hermenêutica jurídica confunde-se com os propósitos de uma teoria da argumentação.

Com as hipóteses trabalhadas, conclui-se que o "evento" da interpretação não tem como base a "vontade", mas uma "escolha" sobre alternativas condicionadas pelas exigências da formação e pelo referente normativo compartilhado nas regras secundárias do costume judicial. A escolha sobre alternativas exige ponderação e a medida da ponderação é encontrada no próprio condicionamento da experiência. A hermenêutica jurídica em sentido abrangente determina-se então como discurso crítico da pré-compreensão. O sentido reduzido e abrangente incide nas situações típicas da "equidade", ou seja, quando o aplicador se encontra posicionado em condição análoga à liberdade do legislador. O discurso crítico da pré-compreensão atua, neste caso, para apontar a existência de estruturas prévias diante de "posições originárias" avaliadas sem mediações. Nas situações de equidade, a investigação dos esquemas formais da dogmática e das regras secundárias pode descobrir razões jurídicas satisfatórias quando se trata da avaliação comparada de interesses que concorrem fora das bases do referente normativo.

\section{REFERÊNCIAS}

ARENDT, Hannah. A vida do espírito: o pensar, o querer, o julgar. Tradução de Cesar Augusto R. de Almeida, Antônio Abranches e Helena Franco Martins. Rio de Janeiro: Civilização Brasileira, 2008.

ARISTÓTELES. Da interpretação. Tradução de José Veríssimo Texeira da Mata. $-1^{\mathrm{a}}$ ed. São Paulo: Editora Unesp, 2013.

BETTI, Emilio. Interpretação da lei e dos atos jurídicos: teoria geral e dogmática. Tradução de Karina Jannini a partir da segunda edição revista e ampliada por Giuliano Crifò; revisão técnica de Denise Agostinetti. São Paulo: Martins Fontes, 2007.

DAVID, René. Os grandes sistemas do direito contemporâneo. Tradução de Hermínio A. Carvalho. $-4^{\mathrm{a}}$ ed. São Paulo: Martins Fontes, 2002.

DWORKIN, Ronald. O império do direito. Tradução de Jefferson Luiz Camargo; revisão técnica de Gildo Sá Leitão Rios. - 2ª ed. São Paulo: Martins Fontes, 2007.

FERRAZ JUNIOR, Tércio Sampaio. Função social da dogmática jurídica. - $2^{\mathrm{a}}$ ed. São Paulo: Atlas, 2015.

GADAMER, Hans-Georg. Verdade e método. Tradução de Flávio Paulo Meurer; revisão da tradução de Enio Paulo Giachini. - 14 a ed. - Petrópolis RJ: Vozes. Bragança Paulista: Editora Universitária São Francisco, 2014.

GRONDIN, Jean. Hermenêutica. Tradução de Marcos Marcionilo. - São Paulo: Parábola Editorial, 2012. 
HABERMAS, Jürgen. Pensamento pós-metafísico - ensaios filosóficos. Tradução de Lumir Nahodil com revisão científica de Alexandre Franco de Sá. Coimbra: Livraria Almedina, 2004.

HART, H. L.A. O conceito de direito. Tradução A. Ribeiro Mendes. $-5^{\text {a }}$ ed. Lisboa: Fundação Calouste Gulbenkian, 2007.

KELSEN, Hans. Teoria geral do direito e do estado. Tradução de Luís Carlos Borges $-4^{\mathrm{a}}$ ed. São Paulo: Martins Fontes, 2005.

Teoria pura do direito. Tradução de João Baptista Machado. - $8^{a}$ ed. São Paulo: Editora WMF Martins Fontes, 2009.

KUHN, Thomas S. A estrutura das revoluções científicas. Tradução de Beatriz Vianna Boeira e Nelson Boeira. - 11 a ed. São Paulo: Perspectiva, 2011.

LAFER, Celso. A reconstrução dos direitos humanos: um diálogo com o pensamento de Hannah Arendt. São Paulo: Companhia das Letras, 2015 ( $8^{a}$ reimpressão).

LLOYD, Dennis. A ideia de lei. Tradução de Álvaro Cabral - $2^{a}$ ed. São Paulo: Martins Fontes, 2000 .

PALMER, Richard E. Hermenêutica. Tradução de Maria Luísa Ribeiro Ferreira. Lisboa: Edições 70, 2006.

PALOMBELLA, Gianluigi. Filosofia do direito. Tradução de Ivone C. Benedetti com revisão técnica de Ari Solon. São Paulo: Martins Fontes, 2005.

RAZ, Joseph. $O$ conceito de sistema jurídico: uma introdução à teoria dos sistemas jurídicos. Tradução de Maria Cecília de Almeida com revisão da tradução de Marcelo Brandão Cipolla. São Paulo: Editora WMF Martins Fontes, 2012.

SEARLE, John R. Consciência e linguagem. Tradução de Plínio Junqueira Smith; revisão técnica de Eunice Ostrensky; revisão de tradução Marcelo Brandão Cipolla e Vadim Niktin. São Paulo: Editora WMF Martins Fontes, 2010.

STRECK, Lenio Luiz. Verdade e consenso. - $6^{\text {a }}$ ed. rev. e ampl. São Paulo: Saraiva, 2017. 
